\title{
Clinical Presentation and Outcome of Bacterial Meningitis in University Hospital
}

\author{
Maimoona Mushtaq Ahmed \\ King Abdulaziz University, Jeddah, KSA \\ Email: maimoonaaa@yahoo.com
}

Received 24 June 2014; revised 24 July 2014; accepted 18 August 2014

Copyright (C) 2014 by author and Scientific Research Publishing Inc.

This work is licensed under the Creative Commons Attribution International License (CC BY). http://creativecommons.org/licenses/by/4.0/

(c) (i) Open Access

\begin{abstract}
Purpose: To determine the clinical characteristics and outcome of bacterial meningitis in adult patients using CT, MRI and CSF culture. Methods: Patients admitted to the university hospital with clinical diagnosis of meningitis were included in the present study. All patients were subjected to clinical examination as well as CT, MRI scanning and CSF-bacteriological culture. Results: The age distribution of the patients shows that there is high frequency of symptoms found in the age group between ages 40 - 45. CSF in the present study included WBS, RBC, glucose and protein, which is associated with the adverse outcome. Meningitis can be confirmed by many methods, in the present study three different methods were used, which included CT scan, MRI and CSF analysis and bacterial culture. In CT scan, among the predictors of meningitis, persons with TB $(P=0.037)$, patients with HIV $(P=0.036)$ and stroke $(P=0.036)$ showed significant association. Whereas MRI findings were significantly associated with $T B$ meningitis $(P=0.015)$. Meningitis was prevalent in the age group of $<45$. Conclusion: This study highlights the importance of several modalities for diagnosing and predicting the outcome of meningitis in adults.
\end{abstract}

\section{Keywords}

Bacterial Meningitis, Diagnosis CT, MRI, CSF Culture, Adult Patients, Saudi Arabia

\section{Introduction}

Meningitis, is the most common infection associated with mortality and morbidity worldwide, thus posing serious public health burden demanding early diagnosis and treatment [1]. Despite advancements in antimicrobial therapy, the prevalence of mortality remains high, especially in developing countries [2] among adults [3]. The causative microorganisms for acute bacterial meningitis are Hemophilius influenza while in some countries, Streptococcus pneumonia [4] [5]. In adults, Hemophilius influenza type-b has been recognized as a pathogen, 
particularly those with underlying illness [6]-[8] or due to failure of natural acquisition of immunity to infection or weaning immunity with aging [9]. In determining the outcome of this infection, the type of organisms, age, early treatment and the duration of disease were found to be important factors [7] [8].

In Kingdom of Saudi Arabia (KSA), the majority of the previous studies on bacterial meningitis were carried out in Children [10]-[12] and only few case reports and one in Yemen [2]. For instance, a case report by Babay et al. [13] reported an association of bacterial meningitis with the previous nasal polypectomy and CSF leak [6] [8] [14] and clinical features of meningitis in adults are similar to those in children [6] [8] [15]. Abdulrab et al., [2] in their retrospective study among 121 adults with acute bacterial meningitis reported the common pathogen was Streptococcus pneumonia, and the mortality rate was $22.3 \%$. Impaired consciousness, recurrent convulsion and chest infection are the most common complications. In general, bacterial meningitis is clinically characterized by fever, headache, malaise, photophobia, rarely confusion, alteration of consciousness stiff neck, irritability, vomiting, acute psychosis and seizures [16]. Further, approximately $10 \%-15 \%$ of the patients' with local neurologic signs were observed. Given the severe nature of these diseases, the diagnosis of bacterial meningitis must be differentiated from other conditions that may be present in similar ways. Based on various identifications, diagnosis has been done by using latex particle agglutination test for antigen detection, microscopy of a gram stained smear, the bacterial pathogen in the cerebrospinal fluid (CSF), and or (b) a low CSF glucose concentration (usually a ratio of CSF: blood glucose of less than 0.3 ), elevated total protein content ( $>120 \mathrm{mg} / \mathrm{dl}$ ) and elevated CSF cell count of more than 1000 white blood cells/ $\mu$ l and CSF consisting of more than $60 \%$ of polymorph nuclear leukocytes. In this condition, several abnormalities in patients are identified by using cranial CT (or MRI) where cerebrovascular involvement may be detected by MRI [16].

To our knowledge, there are few studies on acute meningitis among adults in Saudi Arabia Context. Therefore, the present research attempted to examine the outcome and clinical characteristics among adult patients in Saudi Arabia.

\section{Materials and Methods}

In a retrospective study, of 60 patients (age ranged from $>15$ to 45 years) with clinical symptoms of meningitis admitted in the hospital were included in the study. A special information sheet was designed which included the patient's age, sex, illness duration, clinical signs and symptoms.

Diagnostic inclusion criteria were clinical symptoms and signs of meningitis (e.g., nausea, vomiting, drowsiness, Confusion and disorientation, fever, photophobia, severe headache, neck stiffness, poor appetite, severe irritability [17], plus either a negative culture with a positive CSF or a positive culture from CSF antigen study or blood culture positive with CSF WBC of $>100 / \mathrm{mm}^{3}$, in the absence of bacterial isolate, CSF WBC of $>$ $4000 / \mathrm{mm}^{3}$ or Gram stain in conjunction with a CSF leukocyte concentration (WB) of $>10 / \mathrm{mm}^{3}$ [18]. The information was gathered from clinical presentation, medications taken, duration of illness and demographic features.

Bacterial cultures were performed on Mac Conkey agar medium; the chocolate agar and blood chocolate agar plates were incubated in candle jars at $37^{\circ} \mathrm{C}$ aerobically. The readings were measured after 48 hours and isolates were identified using standard procedures. The laboratory findings which include the analysis of the Cerebrospinal fluid (CSF) such as leucocytes count, glucose, protein level and gram staining and organism culture were analyzed. The course of the disease, complication and its outcomes were assessed. Suspected cases of meningitis were defined as the patients with clinical symptoms of meningitis. For example, fever, headache, neck stiffness, vomiting and change in mental status. A probable case of bacterial meningitis was with turbid CSF [19].

\section{Statistical Analysis}

Outcomes are introduced as mean $( \pm \mathrm{SD})$, and categorical variables are reported in frequencies. By using IBM Corp. Released 2011, Statistical analysis was conducted.IBM SPSS Statistics for Windows, Version 20.0. Armonk, NY: IBM Corp. CT, CFS and MRI findings were computed and compared. Independent sample t-test with $95 \%$ confidence interval was utilized as suitable. $\mathrm{P}<0.05$ was considered significant.

\section{Results}

Present study includes 60 patients admitted for the symptoms of meningitis. The age distribution of the patients showed high frequency of symptoms of infection in the age group $\geq 45$ (30.0) (Figure 1). 


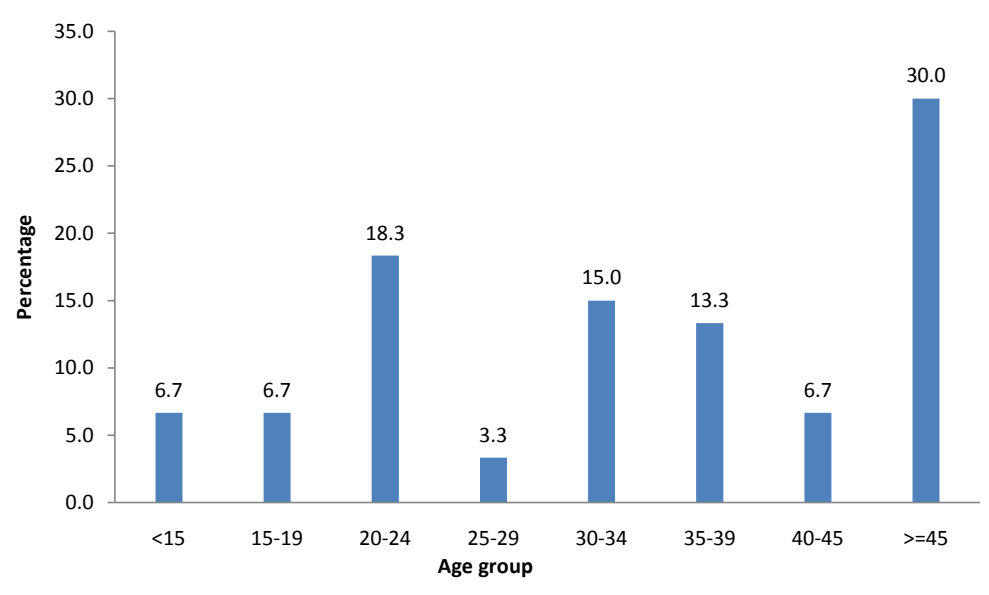

Figure 1. Percentage for age distribution of patients with acute meningitis.

The symptoms like Fever, Headache, vomiting, altered mental status, neck rigidity, photophobia, dizziness were encounter in the patients admitted for the diagnostics of meningitis. Among these symptoms majority of the patients had symptom of fever (80.0\%), followed with altered mental status (70.0\%) (Table 1$)$.

Among 60 patients who were suspected with the symptoms of meningitis, majority were females (71.7\%), belonged to non-Saudi (73.3\%). Patients were admitted with the persistent symptoms like fever $(80.0 \%)$ followed by altered level of consciousness (70.0\%), headache (48.3\%), neck rigidity (41.7\%), fits (31.7\%), vomiting (20.0\%), Photophobia (10.0\%) and dizziness (5.0\%) observed from (Figure 2).

Among the laboratory characteristics of the meningitis infected patients the mean levels of CSF-WBC, CSFRBC, CSF-Glucose and CSF-Protein were $3.41 \pm 2.163 .95 \pm 2.49,3.91 \pm 2.60$ and $1.30 \pm 1.03$ respectively (Table 2).

CSF-WBC—Cerebrospinal fluid white blood cell, CSF-RBC—Cerebrospinal red blood cells, CSF GLU— Cerebrospinal glucose, CSF PROT-Cerebrospinal protein.

There are many treatments associated with meningitis, in the present study during admission 53 (88.3\%) patients with ceftriaxone followed by 52 (86.7\%) patients with vancomycin, 35 (58.3\%) patients with Acyclovir on admission, 13 (21.7\%) patients with change of antibiotics after 24 hours and 8 patients (13.3\%) with TB on admission were observed from (Table 3).

There are many complications associated with meningitis, in the present study 5 (8.3\%) patients with stroke followed by 2 (3.3\%) patients with Cranial nerve palsy, and 2 (3.3\%) patients with hydrocephalous were observed (Table 4).

\subsection{Dependent Variable: Brain CT Scan}

Table 5 presents the unadjusted odds ratios for selected risk factors associated with meningitis by Brain CT findings among participants. The $\mathrm{P}$ value for the symptoms of bacterial meningitis showed greater than 0.05 with Brain CT findings, thus there is no significant association between CT findings of meningitis and symptoms.

\subsection{Dependent Variable: CSF-Culture Findings}

Table 6 shows the unadjusted odds ratios for selected risk factors associated with meningitis by CSF-Culture findings among participants. Since $\mathrm{P}>0.05$ for all the symptoms with CSF-Culture findings, there is no significant association between CSF-Culture findings and symptoms.

\subsection{Dependent Variable: MRI Findings Meningitis Disease}

Table 7 shows the unadjusted odds ratios for selected risk factors associated with meningitis by MRI findings among participants. For all the symptoms $\mathrm{P}$ value is greater than 0.05 with MRI findings of meningitis. Hence, there is no significant association between MRI findings of meningitis and symptoms. 


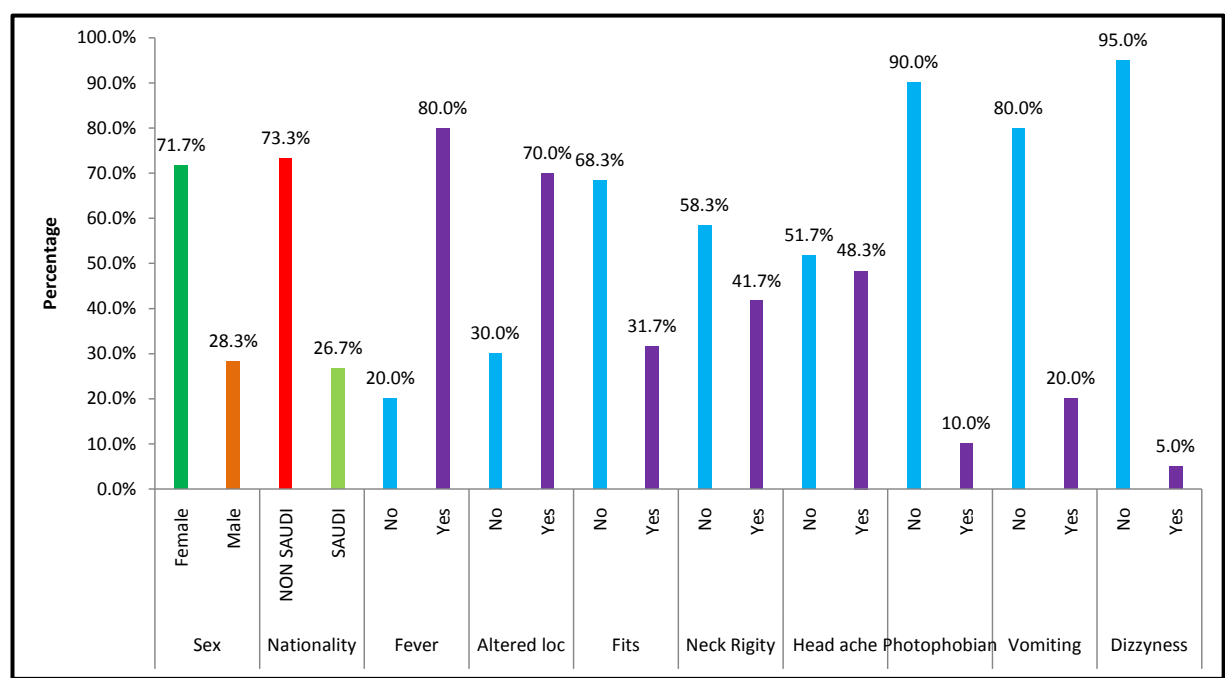

Figure 2. Percentage for baseline demographic and symptoms in meningitis.

Table 1. Symptomsfindings of cases meningitis.

\begin{tabular}{ccc}
\hline Symptoms & Number Patients & Percent (\%) \\
Fever & 48 & $(80.0)$ \\
Headache & 29 & $(48.3)$ \\
Vomiting & 12 & $(20.0)$ \\
Altered Mental Status & 42 & $(70.0)$ \\
Neck Rigidity & 25 & $(41.7)$ \\
Photo Phobia & 6 & $(10.0)$ \\
Dizziness & 3 & $(5.0)$ \\
Fits & 19 & $(31.7)$ \\
\hline
\end{tabular}

Table 2. Laboratory Characteristics of meningitis infected.

\begin{tabular}{ll}
\hline Laboratory & Mean (SD) \\
\hline CSF-WBC & $3.41(2.16)$ \\
CSF-RBC & $3.95(2.49)$ \\
CSF-GLU & $3.91(2.60)$ \\
CSF-PROT & $1.30(1.03)$ \\
\hline
\end{tabular}

Table 3. Treatments associated with meningitis.

\begin{tabular}{cc}
\hline Treatments & Number of Patients (\%) \\
\hline TB on Admission & $8(13.3)$ \\
Ceftrixone on Admission & $53(88.3)$ \\
Vancomicin on Admission & $52(86.7)$ \\
Acylovir on Admission & $35(58.3)$ \\
Change of Antibiotics after 24 Hours & $13(21.7)$ \\
\hline
\end{tabular}


Table 4. Complications associated with meningitis.

\begin{tabular}{cc}
\hline Complication & Number of Patients (\%) \\
\hline Stroke & $5(8.3)$ \\
Cranial Nerve Palsy & $2(3.3)$ \\
Hydrocephalous & $2(3.3)$ \\
\hline
\end{tabular}

Table 5. Binary logistic regression for predicting meningitis disease by CT-Scan.

\begin{tabular}{ccc}
\hline Risk Factors & Odds Ratio (C.I Lower - Upper) & P-Value \\
\hline Fever & $1.200(0.316-4.560)$ & 0.789 \\
Altered Level of Consciousness & $2.625(0.739-9.330)$ & 0.136 \\
Fits & $0.504(0.153-1.666)$ & 0.261 \\
Neck Rigidity & $0.519(0.173-1.558)$ & 0.242 \\
Headache & $0.463(0.157-1.360)$ & 0.306 \\
Photophobia & $0.314(0.034-2.881)$ & 0.354 \\
Vomiting & $0.509(0.122-2.124)$ & 0.297 \\
Dizziness & $3.700(0.316-43.365)$ & 0.25 \\
\hline
\end{tabular}

Table 6. Binary logistics model for predicting meningitis by CSF-Culture findings and risk factors.

\begin{tabular}{ccc}
\hline Risk Factors & Odds Ratio (C.I Lower - Upper) & P-Value \\
\hline Fever & $0.478(0.040-5.762)$ & 0.561 \\
Fits & $1.083(0.092-12.738)$ & 0.949 \\
Neck Rigidity & $0.688(0.059-8.026)$ & 0.765 \\
Headache & $0.518(0.044-6.037)$ & 0.599 \\
\hline
\end{tabular}

Table 7. Binary logistic regression for predicting meningitis disease by MRI.

\begin{tabular}{ccc}
\hline Risk Factors & Odds Ratio (C.I Lower - Upper) & P-Value \\
\hline Fever & $0.462(0.114-1.876)$ & 0.280 \\
Altered Level of Consciousness & $0.955(0.252-3.622)$ & 0.945 \\
Fits & $1.473(0.409-5.300)$ & 0.553 \\
Neck Rigidity & $0.844(0.240-2.969)$ & 0.791 \\
Headache & $1.326(0.387-4.544)$ & 0.654 \\
Vomiting & $0.273(0.032-2.339)$ & 0.094 \\
Dizziness & $8.364(0.694-100.771)$ & \\
\hline
\end{tabular}

\section{Discussion}

Bacterial meningitis was the major cause of meningitis in around two third of cases [20]. The substantial mortality due to meningitis remains as a major medical concern throughout the world. Bacterial meningitis is the major cause of morbidity in children below the age of 5 years [21]. The present study showed that the frequency of meningitis is more prevalent in age group of $\geq 45$ (30.0) which may be due to other socioeconomic factors. Previous studies show that meningitis is indirectly related to family income [22]. In relation to gender based prevalence, 
females were found to be more vulnerable than males, this finding is contradictory with the previous studies, where both gender are equally affected with meningitis [8] [10]. This may be due to the difference in the exposure to the etiological agents.

In the present study the findings of clinical symptoms of the meningitis patients showed that $80 \%$ of the patients were with the symptoms of fever followed by altered mental status $(70.0 \%)$ and Neck rigidity (41.7\%). In the patients suspected with meningitis majority of them were females (71.7\%). The age, duration of the disease and type of treatment were considered as the important factors in determining meningitis [23]. In Arabian countries, epidemiology and the outcome of meningitis were reported in previous studies, however few studies have been published [24] [25]. Among the laboratory characteristics of meningitis the CSF-RBC showed higher mean when compared to that of WBC, GLU and PROT. Perhaps the low CSF leucocytes counts were associated with the development of meningitis. Thus due to the lack of leucocytes other infectious diseases might occur [26] [27].

Meningitis is associated with other complications; patients might take antibiotics for those complications, which eventually aggravate the intensity of meningitis. In the present study, during admission of patients with meningitis, there are patients who were already under the treatment with some antibiotics like anti TB, Ceftriaxone, Vancomicin, Acylovir and some patient's required change of antibiotics after 24 hours. The majority of patients were taking ceftriaxone on admission (88.3\%), where the ceftriaxone is the most frequently recommended for bacterial meningitis [28]. Some patients developed complications like Stroke (8.3\%), Cranial nerve palsy (3.3\%) and Hydrocephalus (3.3\%). Bacterial meningitis is the leading cause of stroke in young patients [29].

Meningitis can be confirmed through many methods, in the present study three different methods were used, which included CT scan, MRI and CFC-Culture. CT scan may be used to find swelling and inflammation in meningitis whereas MRI detects other complications like effusion, venous thrombosis, ventriculitis and hydrocephalus. However, CT detects inflammation in skull or sinuses. MRI is more sensitive, in diagnosing meningitis when compared to CT. Thus, MRI is most preferable in terms of sensitivity. Previous studies revealed that in CT scan, the abnormality appearance was detected as 53\%, whereas in MRI it is 92\% sensitivity, usually CT cannot able to detect small abnormalities in size [30].

In the present study the findings from CT, MRI and CFC showed that there are no significant association statistically between the risk factors of bacterial meningitis and the mode of detection. Whereas all the patients diagnosed showed the symptoms like Head ache, vomiting, neck rigidity, Dizziness, Photophobia, fits, altered level of consciousness and fever with varied percentage.

Among the clinical manifestation of meningitis headache, fever and neck stiffness were common in all patients diagnosed with meningitis Perhaps the percentage of the symptoms differ between the mode (CT, MRI, CFC-Culture) of detecting the disease, due to patient selection. The findings of the present study are in line with the study conducted by [31] where Headache, neck rigidity and fever was documented in the patients. These symptoms might act as a signal in the diagnosis of meningitis patients [12] [32]. However, few previous studies have shown that there is a complete absence of these symptoms of meningitis in adults [32]-[34]. There is a strong association between the meningitis and the previous vaccination history and other associated complication of meningitis [19].

\section{Conclusion}

Present study highlights the major complications of the meningitis and predictors of meningitis in Saudi Arabia. In addition, present study examined the clinical characteristics and outcome among adult patients in Saudi Arabia. Symptoms like fever, altered mental status and neck stiffness were present almost in all patients irrespective of mode of CT, MRI and CFC Culture detection. Hence, supportive care is preferred in special care units of patients with meningitis. Creating awareness and Prevention of meningitis is recommended in order to decrease the meningitis case through vaccination and immunization.

\section{References}

[1] Farag, H.F.M., Abdel-Fattah, M.M. and Youssri, A.M. (2005) Epidemiological, Clinical and Prognostic Profile of Acute Bacterial Meningitis among Children in Alexandria, Egypt. Indian Journal of Medical Microbiology, 23, 95-101. http://www.ncbi.nlm.nih.gov/pubmed/15928437 http://dx.doi.org/10.4103/0255-0857.16047 
[2] Abdulrab, A., Algobaty, F., Salem, A.K. and Mohammed, Y.A. (2010) Acute Bacterial Meningitis in Adults: A Hospital Based Study in Yemen. Japanese Journal of Infectious Diseases, 63, 128-131. http://www.ncbi.nlm.nih.gov/pubmed/20332577

[3] van de Beek, D., de Gans, J., Spanjaard, L., et al. (2004) Clinical Features and Prognostic Factors in Adults with Bacterial Meningitis. The New England Journal of Medicine, 351, 1849-1859. http://www.nejm.org/doi/full/10.1056/NEJMoa040845\#t=articleBackground http://dx.doi.org/10.1056/NEJMoa040845

[4] Zaidi, A., Awasthi, S. and DeSilva, H. (2004) Burden of Infectious Diseases in South Asia. BMJ, 328, 811-815. http://dx.doi.org/10.1136/bmj.328.7443.811

[5] Al-Binali, A.M. and Al-Fifi, S.H. (2002) Profile of Childhood Meningitis in a Hospital in South West Saudi Arabia. Saudi Medical Journal, 23, 793-796. http://www.ncbi.nlm.nih.gov/pubmed/12174227

[6] McGee, Z. and Baringer, J. (1990) Acute Meningitis. In: Mandell, G.L., Bennett, J. and Dolin, R., Eds., Principles and Practice of Infectious Diseases, Churchill Livingstone, New York, 741-755.

[7] Wallace Jr., R.J., Musher, D.M., Septimus, E.J., McGowan Jr., J.E., Quinones, F.J., et al. (1981) Haemophilus influenzae Infections in Adults: Characterization of Strains by Serotypes, Biotypes and ß-Lactamase Production. The Journal of Infectious Diseases, 144, 101-106. http://dx.doi.org/10.1093/infdis/144.2.101

[8] Sigurdardottir, B., Bjornsson, O.M., Jonsdottir, K.E., Erlendsdóttir, H. and Gudmundsson, S. (1997) Acute Bacterial Meningitis in Adults. A 20-Year Overview. Archives of Internal Medicine, 158, 425-430. http://dx.doi.org/10.1001/archinte.1997.00440250077009

[9] Holmes, S.J., Lucas, A.H., Osterholm, M.T., Froeschle, J.E. and Granoff, D.M. (1991) Immunoglobulin Deficiency and Idiotype Expression in Children Developing Haemophilus influenzae Type b Disease after Vaccination with Conjugate Vaccine. The Collaborative Study Group. JAMA, 266, 1960-1965. http://dx.doi.org/10.1001/jama.1991.03470140072027

[10] Azubuike, J.C. (1990) Childhood Bacterial Meningitis in Tabuk, Saudia Arabia. Annals of Saudi Medicine, 10, 145148.

[11] AL-Jurayyan, N. (1992) Childhood Bacterial Meningitis in AL-Baha Provience, Saudia Arabia. The Journal of Tropical Medicine and Hygiene, 95, 180-185.

[12] Srair, H. (1992) Bacterial Meningitis in Saudi Children. Indian Journal of Pediatrics, 59, 719-721. http://dx.doi.org/10.1007/BF02859407

[13] Rabay, H.A., Al Anazy, A.R. and Saidu, A.B. (2003) Case Reports Meningitis in an Adult Immunocompetent Patient. SAUDI Medical Journal, 24, 783-785.

[14] Crawford, C., Kennedy, N. and Weir, W. (1994) Cerebrospinal Fluid Rhinorrhoea and Haemophilus influenzae Meningitis 37 Years after Head Injury. Journal of Infection, 28, 93-97. http://dx.doi.org/10.1016/S0163-4453(94)94378-8

[15] Durand, M.L., Calderwood, S.B., Weber, D.J., Miller, S.I., Southwick, F.S., Caviness Jr., V.S. and Swartz, M.N. (1993) Acute Bacterial Meningitis in Adults-A Review of 493 Episodes. The New England Journal of Medicine, 328, 21-28. http://dx.doi.org/10.1056/NEJM199301073280104

[16] Paul, R., Kastenbauer, S., Koedel, U. and Grosshadern, K. (2003) Complications and Treatment of Bacterial Meningitis. Schweizer Archiv fur Neurologie und Psyshiatrie, 154, 169-173.

[17] Wolf, S. (1978) Laboratory Evaluation of the Child with a Febrile Convulsion. Pediatrics, 62, 1074-1076.

[18] Berkley, J.A., Mwangi, I., Ngetsd, C.J., et al. (2001) Diagnosis of Acute Bacterial Meningitis at a Distant Hospital in Sub-Saharan Africa. The Lancet, 357, 1753-1757. http://dx.doi.org/10.1016/S0140-6736(00)04897-2

[19] Khalfan, S., Ayhmard, M. and Lina, B. (1998) Epidemics of Aseptic Meningitis Due to Enteroviruses Following National Immunization Days in Bahrain. Annals of Tropical Paediatrics, 18, 101-109.

[20] Quagliarello, V. and Scheld, W.M. (1992) Bacterial Meningitis: Pathogenisis, Pathophysiology and Progress. The New England Journal of Medicine, 327, 864-872. http://dx.doi.org/10.1056/NEJM199209173271208

[21] Ahmad, I., Haq, H., Rehman, A., Khattak, A. and Khan, F.M. (2004) Bacterial Meningitis in Children. Journal of Postgraduate Medical Institute, 18, 523-528.

[22] Yost, G.C., Kaplan, A.M. and Bustmante, R. (1986) Bascterial Meningitis in Arizona American Indian Children. American Journal of Diseases of Children, 6, 943-946.

[23] Muhe, L. and Tilahun, M.L.S. (1999) Etiology of Pneumonia, Sepsis and Meningitis in Infants Younger than 3 Months of Age in Ethiopia. Pediatric Infectious Disease Journal, 18, S56-S61.

[24] Tikhomirov, E., Santamaria, M. and Esteves, K. (1997) Meningococcal Diseases: Public Health Burden and Control. World Health Statistics Quarterly, 50, 170-177. 
[25] Salih, M.A., Ahmed, H.S., Karrar, Z.A., Kamil, I., Osman, K.A., Palmgren, H., Hofvander, Y. and Olcén, P. (1990) Features of Large Epidemic Group of Meningococcal Meningitis in Khartoum. Scandinavian Journal of Infectious Diseases, 22, 161-170.

[26] Kastenbauer, S. and Pfister, H. (2003) Pneumococcal Meningitis in Adults: Spectrum of Complications and Prognostic Factors in a Series of 87 Cases. Brain, 126, 1015-1025. http://dx.doi.org/10.1093/brain/awg113

[27] McMillan, D., Lin, C., Aronin, S. and Quagliarello, V. (2001) Community-Acquired Bacterial Meningitis in Adults: Categorization of Causes and Timing of Death. Clinical Infectious Diseases, 33, 969-975. http://dx.doi.org/10.1086/322612

[28] Schaad, U.B., Suter, M.D., Borradori, A.G., Pfenninger, J., Auckenthaler, R., Bernath, O., Cheseaux, J.J. and Wedgwood, J. (1990) Comparison of Ceftriaxone and Cefuroxime for the Treatment of Bacterial Meningitis in Children. The New England Journal of Medicine, 322, 142-147. http://dx.doi.org/10.1056/NEJM199001183220301

[29] Samiullah, S., Humaira, M., Hanif, G., Ghouri, A.A. and Shaikh, K. (2010) Etiological Patterns of Stroke in Young Patients at a Tertiary Care Hospital. Journal of Pakistan Medical Association, 60, 201-204.

[30] Incesu, L., Khosla, A. and Aiello, M. (2009) Imaging in Chiari II Malformation: Imaging eMedicine. http://emedicine.medscape.com/article/406975-overview.

[31] Vaswani, A.K., Nizamani, W.M., Ali, M., Aneel, G., Shahani, B. and Hussain, S. (2014) Diagnostic Accuracy of Contrast-Enhanced FLAIR Magnetic Resonance Imaging in Diagnosis of Meningitis Correlated with CSF Analysis. Radiology, 2014, Article ID: 578986. http://dx.doi.org/10.1155/2014/578986.

[32] Carol, K. and Carrol, C. (1994) A Prospective Investigation of the Long-Term Auditory-Neurological Sequelae Associated with Bacterial Meningitis: A Study from Vanuatu. The Journal of tropical medicine and hygiene, 97, 145-150.

[33] Liu, C.C., Chen, J.S., Lin C.H., et al. (1993) Bacterial Meningitis in Infants and Children in Southern Taiwan Emphasis on H. influenza Type B Infection. Journal of the Formosan Medical Association, 92, 884-888.

[34] Muhe, L. and Tilahun, M.L.S. (1994) Clinical Signs and Etiological Agents of Pneumonia. Clinical Outcome Predictors. Ethiopian Medical Journal, 32, 206. 
Scientific Research Publishing (SCIRP) is one of the largest Open Access journal publishers. It is currently publishing more than 200 open access, online, peer-reviewed journals covering a wide range of academic disciplines. SCIRP serves the worldwide academic communities and contributes to the progress and application of science with its publication.

Other selected journals from SCIRP are listed as below. Submit your manuscript to us via either submit@scirp.org or Online Submission Portal.
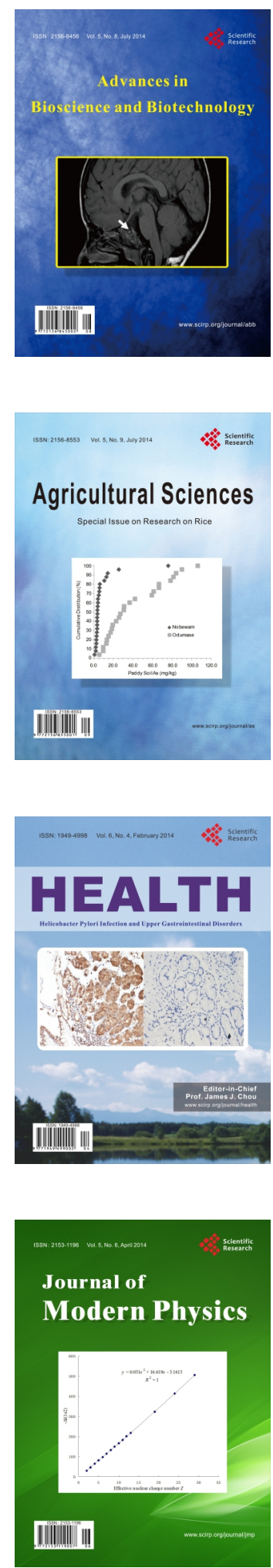
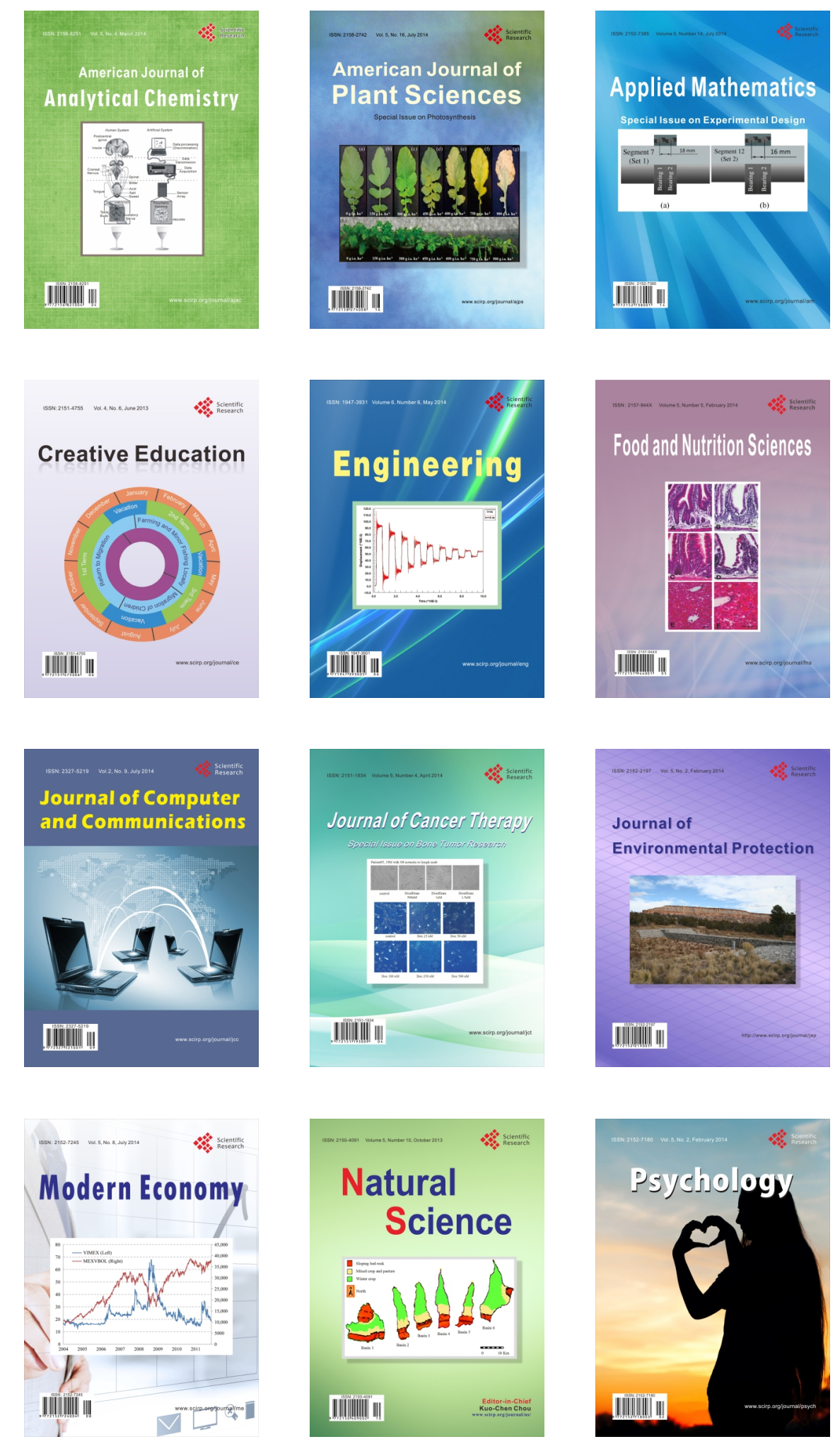